\title{
IMPACTO SOCIAL DA MINERAÇÃO: UMA COMPARAÇÃO ENTRE A PERCEPÇÃO DA EMPRESA E A DA COMUNIDADE
}

\author{
SOCIAL IMPACT OF MINING: A COMPARISON BETWEEN THE \\ THE COMPANY'S AND THE COMMUNITY'S PERCEPTION
}

\section{IMPACTO SOCIAL DE LA MINERÍA: UNA COMPARACIÓN ENTRE LAS PERCEPCIONES DE LA EMPRESA Y DE LA COMUNIDAD}

\author{
Gisela Gerotto \\ Mestranda no Centro Universitário FEI, Brasil \\ gisela@fei.edu.br \\ Viviane Pisano \\ Doutoranda em Administração no Centro \\ Universitário FEI, Brasil \\ vivianemotta@fei.edu.br
}

\section{Jacques Demajorovic}

Docente do Centro Universitário FEI, Brasil

Doutor em Educação pela Universidade de São

Paulo, Brasil

jacquesd@fei.edu.br

\author{
Antonio Aledo \\ Docente da Universidade de Alicante, Espanha \\ Doutor em Sociologia pela Universidade de \\ Alicante, Espanha \\ antonio.aledo@ua.es
}

\author{
Ana Lucia Santiago \\ Doutora em Economia, Empresa e Sociedade pela \\ Universidade de Alicante, Espanha e Centro \\ Universitário FEI, Brasil \\ anasantiago@fei.edu.br
}

\author{
Contextus \\ ISSNe 2178-9258 \\ Organização: Comitê Científico Interinstitucional \\ Editor-Chefe: Diego de Queiroz Machado \\ Editores convidados: Alexandre Graeml; Mônica Cavalcanti \\ Sá de Abreu \\ Avaliação: double blind review pelo SEER/OJS \\ Artigo indicado para fast-track no XLIII Encontro da Anpad \\ (ENANPAD 2019) \\ Recebido em 04/11/2019 \\ Aceito em 04/11/2019 \\ http://dx.doi.org/10.19094/contextus.v17i3.42618
}

\section{RESUMO}

O objetivo desta pesquisa é comparar a percepção de uma comunidade sobre os impactos sociais de um projeto minerário e a percepção da empresa responsável pelo projeto. Os instrumentos para alcançar este objetivo foram a Avaliação de Impacto Social proposto por Aledo e Domínguez-Gómez (2018) e a proposta de categorização de impactos da mineração de Mancini e Sala (2018). A metodologia incluiu a realização de entrevistas e de duas oficinas com representantes da mineradora e da comunidade. Os resultados da pesquisa mostram que o processo de seleção de impactos por parte da empresa foca nos mais imediatos, muitas vezes com viés dos riscos para o negócio, associados à ausência e ineficiência do poder público em apoiar projetos de desenvolvimento local. Já o olhar da comunidade avança além dos impactos mais imediatos, como oferta e qualidade da água e queda na produção agrícola, para questões subjetivas e culturais associadas aos processos de mudança. Infere-se que a visão parcial dos impactos por parte da empresa fragiliza a estratégia de projetos sociais compensatórios. As questões mais profundas associadas aos impactos, como a perda do sentimento de coletividade e o impacto do processo migratório no esgarçamento dos laços familiares, são desconsideradas na escolha e implementação de projetos na comunidade.

Palavras-chave: Avaliação de impacto social; mineração; comunidade local; risco social; percepção dos impactos sociais. 


\begin{abstract}
The purpose of this research is to compare a community's perception of a mining project's social impacts and the perception of the company responsible for the project. The instruments to achieve this were the Social Impact Assessment proposed by Aledo and Domínguez-Gómez (2018) and the proposed categorization of mining impacts by Mancini and Sala (2018). The methodology included interviews and two workshops with representatives of the mining company and the community. The results show that the company's process of selecting impacts focuses on the most immediate, often business-biased risks associated with the government's absence and inefficiency to support local development projects. The community's view, however, goes beyond the most immediate impacts, such as water supply and quality as well as the decrease in agricultural production, towards subjective and cultural issues associated with the processes of change. It is inferred that the partial view of impacts by the company weakens the strategy of compensatory social projects. The deeper issues associated with impacts, such as the loss of collective sentiment and the impact of the migratory process on the severity of family ties, are disregarded while choosing and implementing projects in the community.
\end{abstract}

Keywords: Social Impact Assessment; Mining; Local Community; Social Risk; Perception of social impacts.

\title{
RESUMEN
}

El objetivo de esta investigación es comparar la percepción de una comunidad sobre los impactos sociales de un proyecto minero y la percepción de la empresa responsable del proyecto. Los instrumentos para lograr esto fueron la Evaluación de Impacto Social propuesta por Aledo y Domínguez-Gómez (2018) y la categorización propuesta de los impactos mineros de Mancini y Sala (2018). La metodología incluyó entrevistas y dos talleres con representantes de la empresa minera y la comunidad. Los resultados de la encuesta muestran que el proceso de selección de impactos de la compañía se enfoca en los más inmediatos, a menudo sesgados a los negocios, asociados con la ausencia e ineficiencia del gobierno para apoyar proyectos de desarrollo local. La opinión de la comunidad, sin embargo, avanza más allá de los impactos más inmediatos, como el suministro y la calidad del agua y la caída de la producción agrícola, hacia cuestiones subjetivas y culturales asociadas con los procesos de cambio. Se infiere que la visión parcial de los impactos de la empresa debilita la estrategia de los proyectos sociales compensatorios. Los problemas más profundos asociados con los impactos, como la pérdida del sentimiento colectivo y el impacto del proceso migratorio en la severidad de los lazos familiares, no se tienen en cuenta en la elección e implementación de proyectos en la comunidad.

Palabras clave: Evaluación de impacto social; minería; comunidad local; riesgo social; percepción de los impactos sociales.

\section{INTRODUÇÃO}

A contribuição econômica da atividade extrativista para a economia global é amplamente reconhecida uma vez que estes permeiam quase a totalidade de produtos e serviços considerados essenciais (MANCINI; SALA, 2018). Para alguns países da OCDE, esta atividade assume posição central na construção do PIB e suas exportações. Na Austrália, o setor de mineração representa 57,3\% das exportações e 10\% de seu PIB, enquanto na Papua Nova Guine estes percentuais chegam 51\% das exportações e 26\% do PIB (FOO; BLOCK; SALIM, 2018). Por outro lado, a extração de minérios é bastante impactante ao meio ambiente e à comunidade que vive no entorno da operação (ESTEVES; VANCLAY, 2009). A maior conscientização das comunidades em relação a estes impactos também contribuiu para o aumento de conflitos envolvendo mineradoras e a população local que desafiam os processos de tomada de decisão de gestores do setor (MCMAHON; REMY, 2003). A partir de estudos de caso empíricos, Franks et al. (2014) identificaram os conflitos mais comuns que surgem em áreas de mineração, destacando-se os conflitos em torno de impactos ambientais, da saúde da comunidade e da 
distribuição justa dos recursos gerados. Além disso, os autores mostram a relação destes conflitos com o aumento de custos de implementação e operação de projetos, incluindo modificações em projetos, paradas na operação e perda de valor no mercado.

De forma a lidar com este contexto, as empresas devem aprimorar suas abordagens na avaliação de risco e no impacto social para reduzir os efeitos negativos da operação e maximizar benefícios. Kemp, Worden e Owen (2016) argumentam que alcançar estes objetivos no setor de mineração é desafiador, porque o uso de termo risco social é feito sem uma adequada diferenciação entre o risco para o negócio e o risco para a comunidade.

Na prática, a avaliação e gestão de riscos é aplicada a partir de uma abordagem técnicocientífica derivada das ciências exatas em detrimento da abordagem social de risco, derivada das ciências humanas. Dessa forma, perde-se nesse processo um entendimento mais amplo do fenômeno, uma vez que é desconsiderada a contribuição teórica das ciências sociais entendendo os riscos como construção social (ALEDO; DOMÍNGUEZ-GÓMEZ, 2018). Barclay, Franks e Pettenden (2009) defendem que, ao considerar riscos sociais na mineração, o risco para o negócio gerado por stakeholders é priorizado em relação aos riscos para comunidade e meio ambiente. Infere-se que esta tradição do entendimento dos riscos sociais no setor de mineração limita também sua percepção em relação aos impactos de suas operações levando ao entendimento distinto de como a comunidade experimenta os impactos associados à operação. Impactos desconsiderados e subavaliados podem potencializar danos na comunidade resultando em conflitos e perda de apoio ao projeto (ALEDO; DOMÍNGUEZ-GÓMEZ, 2018).

Embora uma produção científica robusta sobre impactos gerados por empreendimentos minerários tenha sido produzida nas últimas décadas (VANCLAY, 2002; MANCINI; SALA, 2018), há um número reduzido de estudos focados na percepção de impactos de empresas e comunidade em relação a projetos de mineração e a influência no processo de identificação e priorização dos mesmos. Argumenta-se neste trabalho que, sem subestimar o enfoque técnicocientífico no debate sobre riscos e impactos no setor de mineração, é preciso incorporar também um enfoque construtivista e participativo. Valorizar este em detrimento do enfoque instrumental não se restringe, conforme Aledo e Dominguéz-Gómez (2018), a uma escolha entre diferentes abordagens. É também uma posição política do pesquisador, que realça o contexto social em que o risco é produzido e os valores das pessoas com a função de medir o risco. Em suma, busca-se ampliar a comunidade de avaliadores na identificação dos riscos sociais buscando um entendimento mais sistêmico e abrangente dos fenômenos de geração de riscos e impacto associados a projetos com potencial de causar transformações profundas nos 
territórios em que se encontram.

Nos anos recentes, pesquisas têm ressaltado a importância de aplicar a Avaliação de Impacto Social (AIS) como um processo efetivo de identificar, antecipadamente, as consequências de uma ação real ou de um projeto (JOYCE; MACFARLANE, 2001). A partir de um paradigma construtivista, a AIS propõe metodologias participativas (WEBLER; KASTENHOLZ; RENN, 1995; ESTEVES; FRANKS; VANCLAY, 2012) com uma abordagem bottom-up, que busca assegurar presença e voz às populações mais vulneráveis e afetadas na comunidade dos avaliadores, bem como um processo de identificar e gerir riscos e impactos sociais que reduza os danos à comunidade e maximize benefícios (ALEDO; DOMÍNGUEZ-GÓMEZ, 2018).

Nesse contexto, a questão central desta pesquisa é analisar como a percepção de impactos da empresa e comunidade em relação a projetos de mineração influencia o processo de identificação e priorização de impactos. Já o objetivo da pesquisa é identificar e comparar a percepção da empresa e a da comunidade local sobre os impactos sociais de um projeto minerário. Para alcançar este objetivo, o trabalho está estruturado da seguinte forma, além desta introdução. A sessão 2 discute a evolução teórica da AIS e sua incorporação na mineração, bem como apresenta a proposta de Mancini e Sala (2018) de categorizar impactos da mineração. Na sessão 3, são apresentados os procedimentos metodológicos adotados para a pesquisa de campo. A sessão 4 foca nos resultados do campo e em sua discussão à luz da literatura. Por fim, a sessão 5 explora os principais insights da pesquisa e sua contribuição para o avanço teórico e práticas da AIS na mineração. Acredita-se que a pesquisa evidencia a contribuição das ciências sociais para melhorar os processos de avaliação de riscos e impactos sociais. Além disso, pode contribuir também para avançar as práticas gerenciais, uma vez que, ao dar voz aos impactados, revela também limites e contradições, percebidos ou não pelas empresas, de seus projetos de compensação em territórios afetados pelas atividades de mineração.

\section{Avaliação de impacto social e o setor de mineração}

\subsection{Evolução da metodologia de avaliação de impacto social}

A AIS é uma evolução da Avaliação de Impacto Ambiental (AIA) que surge no início da década de 1970 em resposta aos requisitos da legislação ambiental americana com a NEPA - National Environmental Policy Act (JOYCE; MACFARLANE, 2001). Havia a preocupação 
em relação ao que aconteceria quando o meio sofresse alteração de determinado empreendimento e, por exigência legal, os projetos federais americanos deveriam fazer uma análise prévia dos possíveis impactos. A AIA continuou na década seguinte como o principal instrumento para identificar e mitigar os efeitos colaterais dos projetos, mas no início dos anos 1990 esta abordagem passa a ser criticada por se mostrar insuficiente e limitada para o correto gerenciamento dos riscos sociais trazidos por grandes projetos. As tendências normativas em nível global passam a reconhecer a necessidade de avaliar os aspectos sociais afetados pelas principais intervenções no território. Aledo e Domínguez-Gómez (2018) complementam que o fator humano entrou em pauta quando as grandes alterações dos processos sociais nos locais dos empreendimentos começaram a se destacar.

A AIS é definida como o processo de analisar (prever, avaliar e refletir) e gerenciar as consequências previstas e imprevistas sobre as comunidades no entorno de intervenções planejadas e de processos de mudança social decorrentes de tais atividades com o objetivo de construir um entorno humano e biofísico mais justo e sustentável (VANCLAY, 2003, p. 6).

A importância da AIS se dava, inicialmente, em momentos de aprovação de projetos, cumprimento contratual para captação de financiamento, entre outros (JOYCE; MACFARLANE, 2001; ESTEVES; FRANKS; VANCLAY, 2012). A AIS estuda os efeitos que projetos de intervenção causam nas pessoas, com o objetivo de maximizar suas consequências positivas e eliminar, mitigar, diminuir ou compensar seus efeitos negativos. Neste sentido, as propostas mais inovadoras da AIS não se limitam a identificar impactos, mas avançam na gestão de riscos e de impactos sociais (JOYCE; MACFARLANE, 2001; ESTEVES; FRANKS; VANCLAY, 2012). Isso pode ser alcançado percebendo a AIS como uma ferramenta de gestão com potencial para fornecer informações e auxiliar na tomada de decisão (JOYCE; MACFARLANE, 2001; ALEDO; DOMÍNGUEZ-GÓMEZ, 2018). Esteves et al. (2017) argumentam que a AIS pode servir como instrumento a facilitar a identificação precoce e melhorar a análise e gestão contínua dos riscos sociais e de direitos humanos quando a empresa os insere no sistema de gestão do projeto. Assim, a AIS não se limita à identificação dos impactos para um melhor planejamento de um projeto de forma a mitigar futuros danos à comunidade em seu entorno. Considerando que os impactos de um projeto ao longo de sua operação se transforam e são ressignificados pela população impactada, a AIS deve ser utilizada como uma ferramenta de monitoramento e gestão de forma contínua reduzindo seus impactos negativos e potencializando benefícios na comunidade (JOYCE; MACFARLANE, 2001; ESTEVES et al., 2017; ALEDO; DOMÍNGUEZ-GÓMEZ, 2018). Vale salientar que a gestão 
de riscos e impactos sociais é uma tarefa complexa e repleta de desafios na medida em que não se trata de um exercício objetivo e neutro, considerando que os impactos sociais são experimentados de diferentes maneiras pelos distintos grupos de pessoas afetadas. Sua medição é, em muitas ocasiões, complexa e requer novos paradigmas capazes de enfrentar esses desafios (ALEDO; DOMÍNGUEZ-GÓMEZ, 2018).

A prática empresarial apresenta certa fragilidade na aplicação da AIS, pois não existe um método padrão e há carência de um modelo que se apresente consistente e com reconhecimento internacional (JOYCE; MACFARLANE, 2001). Esta carência se amplifica na medida em que os tomadores de decisão têm diferentes maneiras de entender e interpretar a realidade social. Estas formas de interpretação interferem na confiança e no interesse pela ferramenta de gestão, além de salientar as diferenças entre os dois principais paradigmas científicos nos quais a AIS está embasada: o técnico-científico e o construtivista (ALEDO; DOMÍNGUEZ-GÓMEZ, 2018).

O técnico-científico tem o foco nos riscos tecnológicos ou riscos para o negócio, ou seja, como os stakeholders podem afetar as organizações e como as organizações podem se defender desta ameaça. Na abordagem técnico-científica da AIS, há uma visão incompleta dos impactos sociais por utilizarem metodologias focadas em probabilidade (KEMP; WORDEN; OWEN, 2016). Já o enfoque construtivista parte dos riscos do negócio para os stakeholders externos, mais especificamente, para a comunidade local. As questões centrais estão em responder como o negócio afeta a comunidade, que riscos apresentam maiores impactos negativos e quais seriam as medidas preventivas para mitigar as consequências. Tais questões tornam complexos o entendimento do risco social sendo necessária uma integração de vários departamentos da empresa e a comunidade na identificação dos riscos. Este enfoque privilegia o entendimento de riscos a partir de uma construção social e participativa e não puramente técnica, além de incluir o contexto social em que o risco é produzido e os valores das pessoas que têm a função de medir o risco (ALEDO; DOMÍNGUEZ-GÓMEZ, 2018).

Nesta abordagem, o impacto social tem relação com os processos de mudança gerados pelo projeto. Vanclay (2002) argumenta que uma mudança social pode ou não causar um impacto social, salientando que impacto social tem relação com a percepção e aspectos cognitivos experimentados pelas pessoas. Assim, o aumento do fluxo migratório para uma região de mineração não constitui impacto e sim um processo de mudança para o território. Os impactos serão consequências dessa mudança que poderiam se constituir em aumento de preços de moradia, aumento da violência, entre outros. Ressalta-se ainda que os impactos são subjetivos na medida em que são sentidos, percebidos cognitivamente e vividos, fisicamente, 
pelos indivíduos que são diretamente afetados pelos processos de mudança. Ocorre um impacto social quando o conjunto de informações armazenadas por intermédio da experiência, introspecção ou da aprendizagem de uma comunidade é modificado, causando alteração na forma como as pessoas vivem e se manifestam culturalmente. Vanclay (2002) exemplifica esta distinção por meio de um processo de reassentamento. Este pode levar a movimentos migratórios do campo para cidade e, consequentemente, causar redução na produção agrícola e na renda dos pequenos agricultores. A mudança social é o processo de reassentamento, já a redução da produção agrícola e da renda dos agricultores são os impactos sociais. O impacto social não está no reassentamento de famílias (mudança de local físico) e sim no que acontecem com o estilo de vida, as redes e cultura local (mudança cognitiva).

Projetos minerários têm um enorme potencial de gerar este tipo de mudança nos territórios. Ainda assim, pouca atenção era dada às questões sociais incluindo as questões de direitos humanos, especulação imobiliária, violência, questões de gênero, prostituição, entre outros. A seguir detalha-se como a AIS passa a ganhar relevância no debate sobre mineração e os principais impactos da atividade.

\subsection{A Integração da avaliação de impacto social na mineração}

O interesse em aplicar avaliações de impacto social no âmbito da atividade de mineração começa no final dos anos 1980 (HOWITT, 1989). Canadá e Austrália foram os primeiros países que adotarem este tipo de avaliação que se centraram nos efeitos sobre a população indígena, tanto por sua situação de vulnerabilidade como porque uma parte significativa de projetos de mineração estavam planejados sobre seu território. Durante a década de 1990, o setor mineral começou a perceber a necessidade de integrar as visões técnica e política da AIS, a fim de melhorar a articulação da avaliação social com o planejamento do projeto (LANE; ROSS; DALE, 1997). Além disso, a maior exposição de grandes acidentes envolvendo importantes mineradoras tendo como consequência volumosas compensações financeiras estimulam o maior interesse pela AIS (MIRANDA et al., 2003).

No entanto, foi a partir do ano de 2000 que se ampliou significativamente a produção científica da AIS em projetos de mineração. A partir de uma pesquisa na base de dados Web of Science, utilizando as palavras-chave "social impact assessment" e "mining", verificou-se que, até o final da década de 1990, registraram-se 3 artigos, enquanto no período de 2000 a 2018 foram publicados 79 artigos. 
Vanclay (2002) argumenta que os impactos são uma construção social e cognitiva e, corroborando com Solomon, Katz e Lovel (2008), defende uma abordagem integrativa vinculando a visão técnico-científica à visão construtivista de forma a lidar com a complexidade associada a projetos minerários.

O desenvolvimento da AIS ao longo dos anos 2000 também passa a se relacionar com o ciclo de vida do projeto. Entender os potenciais impactos de cada etapa, incluindo a pesquisa mineral, construção de instalações do empreendimento, operação (extração, beneficiamento e transporte dos minérios) até a etapa de fechamento da mina (JOYCE; MACFARLANE, 2001) (MIRANDA et al., 2003). Os autores destacam também outras variáveis, tais como: tamanho, tempo de vida, localização, tipo de depósito mineral e legislação local levando a uma complexificação do processo de identificar e quantificar os impactos (ESTEVES; VANCLAY, 2009).

O avanço do debate passa a focar em uma melhor qualificação dos impactos sociais. Distingue-se dessa forma da produção nos anos anteriores quando os impactos se restringiam ao deslocamento da população e indenização financeira das terras. Já na primeira década de 2000, as pesquisas tratam de impactos diretos, indiretos (VANCLAY, 2002), cumulativos e induzidos (JOYCE; MACFARLANE, 2001; FRANKS; BRERETON; MORAN, 2013).

A partir de 2010, a AIS avança na discussão da aplicação em diferentes contextos regionais. Os artigos abordam as diferenças da AIS em países desenvolvidos e em países que se encontram em estágio de desenvolvimento (ESTEVES; FRANKS; VANCLAY, 2012). A legislação e as condições de licenciamento nos países em desenvolvimento se mostram menos rigorosas (FRANKS; BRERETON; MORAN, 2013) e o aspecto da vulnerabilidade social ganha maior relevância na produção acadêmica (CLIMENT-GIL; ALEDO; VALLEJOSROMERO, 2018).

Inicia-se ainda um processo de institucionalização da AIS. Surgem documentos direcionadores de instituições financeiras e declarações de organismos multilaterais orientando os investimentos na área mineral. Também nas políticas públicas, a AIS ganha mais espaço, acompanhada de uma maior receptividade desta ferramenta no universo corporativo. (FRANKS; VANCLAY, 2013; HARVEY; BICE, 2014). A AIS passa a ser considerada a oportunidade para os reguladores embasarem suas decisões de forma que os impactos sejam gerenciados em todo o ciclo vida do projeto (FRANKS; VANCLAY, 2013; FRANKS; BRERETON; MORAN, 2013). 
Harvey e Bice (2014) e Hansen et al. (2016) defendem que os tomadores de decisão devem estar cientes das consequências de suas decisões antes de agir e considerar que a população afetada pelo projeto não deve ser somente informada dos potenciais efeitos, mas sim ter a oportunidade de participar da discussão sobre o futuro do território. Harvey e Bice (2014), de um lado, argumentam que as consultas à comunidade propiciam chances maiores de resultados duradouros e vínculos de longo prazo entre empresas e comunidade. Já Hansen et al. (2016), de outro, sustentam que se a comunidade sente que está sendo compensada de maneira inadequada ou leviana, as tensões e conflitos influenciarão o andamento do projeto (HANSEN et al., 2016). Por isso, a tolerância aos impactos negativos aumenta quando a comunidade percebe que os benefícios estão sendo distribuídos de forma mais equitativa indo ao encontro de seus interesses e não apenas aos da empresa (ESTEVES et al., 2017).

Nesse sentido, qualificar de forma mais precisa os impactos sociais positivos e negativos da atividade de mineração tornou-se um foco importante do debate na literatura recente. Rosyida, Khan e Sasaoka (2018) mostram em estudo na Indonésia que a atividade de mineração beneficiou o crescimento e a melhoria da infraestrutura. Entretanto, a distribuição desequilibrada de impactos negativos e benefícios das operações de extração mineral afetou os meios de subsistência das comunidades, sendo um deles a agricultura, considerada um meio de vida para os moradores locais. A extrema dependência econômica das regiões e municípios que concentram operações minerais também é indicada por Atienza, Lufin e Soto (2018), acentuada pela incapacidade do governo e empresas em oferecer estratégias e oportunidades de subsistência a longo prazo para os residentes (BRAIN, 2017).

Uma importante contribuição no entendimento mais amplo e integrado dos impactos sociais na mineração é a pesquisa de Mancini e Sala (2018) a partir de revisão de 50 artigos nessa temática (ver Quadro 1). A pesquisa resultou na identificação de 42 impactos organizados em 6 categorias: economia, renda e proteção; emprego e educação; uso da terra e aspectos territoriais; meio ambiente, saúde e segurança; demografia e direitos humanos. 
Quadro 1 - Categorização e descrição de impactos na mineração

\begin{tabular}{|c|c|c|}
\hline $\begin{array}{l}\text { Categoria do } \\
\text { Impacto }\end{array}$ & $\begin{array}{l}\text { Positivo / } \\
\text { Negativo }\end{array}$ & Descrição do Impacto \\
\hline \multirow{12}{*}{$\begin{array}{l}\text { Economia, Renda } \\
\text { e Proteção }\end{array}$} & \multirow{4}{*}{$\begin{array}{l}\text { Impactos } \\
\text { Positivos }\end{array}$} & Contribuição para economia local \\
\hline & & Aumento nas exportações e no PIB \\
\hline & & Alívio da pobreza \\
\hline & & Oportunidades de negócios e emprego em outros setores devido à economia revitalizada e ao mercado \\
\hline & \multirow{8}{*}{$\begin{array}{l}\text { Impactos } \\
\text { Negativos }\end{array}$} & Suborno (para obter licenças e autorizações ou para influenciar a decisão judicial) e corrupção (devido à má gestão da riqueza mineral) \\
\hline & & Roubos e acidentes na comunidade minerária \\
\hline & & Desigualdade econômica \\
\hline & & Baixo nível de estímulo econômico da mineração devido à prevalência de trabalhadores não residentes \\
\hline & & $\begin{array}{l}\text { Conflitos e tensões sociais em função da distribuição desigual de benefícios e custos com as comunidades ou acesso limitado aos } \\
\text { recursos }\end{array}$ \\
\hline & & Conflitos entre empresa e mineradores ilegais; matanças politicamente motivadas de ativistas anti mineração \\
\hline & & Resultado econômico adverso, aumento da pobreza devido à perda de meios de sustento \\
\hline & & O fracasso do governo em reinvestir as receitas da mineração \\
\hline \multirow{12}{*}{$\begin{array}{c}\text { Emprego e } \\
\text { Educação }\end{array}$} & \multirow{3}{*}{$\begin{array}{l}\text { Impactos } \\
\text { Positivos }\end{array}$} & Aumento de empregos (diretos ou indiretos na comunidade local) \\
\hline & & Aumento de empregos na economia nacional \\
\hline & & Desenvolvimento das habilidades dos funcionários e da educação em geral \\
\hline & \multirow{9}{*}{$\begin{array}{l}\text { Impactos } \\
\text { Negativos }\end{array}$} & Trabalho infantil, trabalho forçado ou compulsório \\
\hline & & Más condições de trabalho e baixos salários \\
\hline & & Impactos na saúde dos trabalhadores, fatalidades e acidentes de trabalho \\
\hline & & Habitação abaixo do padrão fornecida aos trabalhadores \\
\hline & & $\begin{array}{l}\text { Falta de liberdade para se organizar em sindicatos e não conformidade com os requisitos das convenções da Organização Internacional do } \\
\text { Trabalho }\end{array}$ \\
\hline & & Criação de vagas para trabalhos temporários maior que vagas permanentes \\
\hline & & Baixa estabilidade de emprego e de mão de obra \\
\hline & & Aumento do desemprego \\
\hline & & Emprego volátil devido à dependência do preço dos minerais \\
\hline \multirow{5}{*}{$\begin{array}{l}\text { Uso da Terra e } \\
\text { aspectos } \\
\text { territoriais }\end{array}$} & \multirow{2}{*}{$\begin{array}{l}\text { Impactos } \\
\text { Positivos }\end{array}$} & Infra-estruturas melhoradas (telecomunicações, rede rodoviária, energia e abastecimento de água) \\
\hline & & Aumento de acesso à Saúde e Educação \\
\hline & \multirow{3}{*}{$\begin{array}{l}\text { Impactos } \\
\text { Negativos }\end{array}$} & $\begin{array}{l}\text { Expropriação, deslocamento populacional e reassentamento (e consequente desemprego, falta de terra, falta de moradia, perda de recursos } \\
\text { comuns, empobrecimento dos padrões de vida) }\end{array}$ \\
\hline & & Aquisição forçada de terra \\
\hline & & Acesso limitado à terra e consequente impacto nos meios de subsistência, insegurança alimentar e perda de áreas protegidas \\
\hline \multirow{3}{*}{ Demografia } & \begin{tabular}{|l|l|l} 
Impactos \\
Positivos
\end{tabular} & Impactos positivos em função de mudanças demográficas e crescimento populacional \\
\hline & \multirow[t]{2}{*}{$\begin{array}{l}\text { Impactos } \\
\text { Negativos }\end{array}$} & $\begin{array}{l}\text { Crescimento populacional, influxo migratório e desequilíbrio de gênero nas comunidades de mineração (e consequente alcoolismo, } \\
\text { drogas e prostituição, disseminação do HIV, violência doméstica, violência sexual, mudança nas normas sociais, cultura e costumes, } \\
\text { migração, rotatividade escolar }\end{array}$ \\
\hline & & Inflação, aumento dos custos e acesso de alojamento para trabalhadores que não sejam mineradores \\
\hline \multirow{4}{*}{$\begin{array}{l}\text { Meio Ambiente, } \\
\text { Saúde e Segurança }\end{array}$} & \multirow{4}{*}{$\begin{array}{l}\text { Impactos } \\
\text { Negativos }\end{array}$} & $\begin{array}{l}\text { Redução do abastecimento de água ou contaminação da água, competição com outros usos (por exemplo, agricultura) e aumento da } \\
\text { escassez de água }\end{array}$ \\
\hline & & $\begin{array}{l}\text { Impactos negativos de saúde e segurança na comunidade de mineração (por exemplo, danos causados a habitações por explosivos, lesões } \\
\text { relacionadas à mineração durante a atividade mineira em expansão) }\end{array}$ \\
\hline & & $\begin{array}{l}\text { Impactos sociais relacionados aos ciclos de expansão / recessão (por exemplo, aumento de gravidez, infecções sexualmente } \\
\text { transmissíveis, problemas de saúde mental como depressão e ansiedade; questões de saúde da comunidade advindas de períodos de } \\
\text { expansão e retração que incluem encargos sociais e de saúde, estresse familiar, violência contra as mulheres, etc. }\end{array}$ \\
\hline & & Impactos ambientais que afetam condições sociais e de saúde \\
\hline \multirow{6}{*}{ Direitos Humanos } & \multirow{6}{*}{$\begin{array}{c}\text { Impactos } \\
\text { Negativos }\end{array}$} & Abuso aos Direitos Humanos \\
\hline & & Impactos nos recursos culturais e estéticos \\
\hline & & Falta de inclusão dos stakeholders e não envolvimento de comunidades indígenas \\
\hline & & Falta de consenso informado e aceitação social \\
\hline & & $\begin{array}{l}\text { Oportunidades desiguais e discriminação (baseado em gênero, grupos vulneráveis à marginalidade, por exemplo: deficientes, idosos, } \\
\text { minorias étnicas, indígenas, jovens) }\end{array}$ \\
\hline & & Falta de respeito aos direitos dos povos indígenas \\
\hline
\end{tabular}

Nota. Fonte: Recuperado de "Social impact assessment in the mining sector: Review and comparison of indicators frameworks" de L. Mancini e S. Sala, 2018, Resources Policy, 57, p.98-111.

Fonte: adaptado de Mancini e Sala (2018)

Considerando os resultados sintetizados por Mancini e Sala (2018) verifica-se uma maior frequência nos estudos analisados de impactos negativos em relação aos positivos. De um total de 41 impactos identificados, 10 são positivos e 32 negativos. A pesquisa revela ainda que a categoria "economia e renda" apresenta a frequência mais alta de impactos, considerando os positivos e negativos. Já a categoria "meio ambiente, saúde e segurança" apresenta a maior frequência de impactos negativos, seguido pelas categorias "direitos humanos" e "uso da terra". 
Destaca-se que não foram encontrados impactos positivos nas categorias "meio ambiente, saúde e segurança", nem na categoria "direitos humanos". Em relação aos impactos positivos, verificou-se que somente na categoria "emprego e educação", os impactos positivos aparecem com maior frequência que os negativos.

Outro resultado significativo diz respeito à distribuição geográfica dos impactos. $\mathrm{O}$ estudo identificou que impactos relativos ao aumento de renda, negócios e problemas ambientais que afetam a saúde aparecem tanto em países desenvolvidos quanto em países em desenvolvimento. Por outro lado, impactos relacionados ao uso da terra e expropriação são mais frequentes em países em desenvolvimento. Estudos da Austrália apresentam impactos positivos em 50\% dos casos, e esses impactos se referem a "economia e renda", "demografia" e “emprego". No sentido oposto, a África tem o maior número de impactos totais, sendo que 76\% deles são negativos e estão relacionados ao "uso da terra" e "economia e renda".

Estas categorias estabelecidas por Mancini e Sala (2018) possibilitaram uma primeira análise dos dados coletados neste estudo. A partir dessas categorias e comparando a identificação realizada pela empresa e a levada a cabo pela comunidade, foi possível estabelecer quais áreas de impacto são prioritárias para estes dois stakeholders, onde estão os pontos em comum e quais são as área conflitivas. Uma explicação mais detalhada da metodologia aplicada é apresentada na próxima sessão.

\section{METODOLOGIA}

\subsection{Descrição do estudo de caso}

Considerando a importância da singularidade no processo de escolha do estudo de caso, a seleção do território analisado se justifica por se tratar da maior província mineral do Brasil e pelo fato do empreendimento e a comunidade se encontrarem dentro de uma Área de Proteção Ambiental (APA) situada na região amazônica. Seu processo de povoamento teve início nos anos 1980 através de ações de ocupação de terras organizadas por movimentos sociais, sendo mais tarde transformada em APA. A comunidade é uma área bastante próxima da mina de extração e da barragem de rejeitos da mineradora. 


\subsection{Coleta de dados}

Com o objetivo de identificar e comparar a percepção dos impactos sociais de um projeto minerário na visão da empresa e da comunidade local propõe-se uma pesquisa exploratória, qualitativa e aplicada, realizada por meio de um estudo de caso único. A opção pela realização de um estudo de caso se deu em função da necessidade de se entender um fenômeno social complexo (YIN, 2015), permitindo compreender a dinâmica apresentada dentro de contextos específicos (EISENHARDT, 1989). Considerando a importância da singularidade no processo de escolha do estudo de caso, a seleção do território analisado se justifica por se tratar da maior província mineral do Brasil e pelo fato do empreendimento e a comunidade se encontrarem dentro de uma Área de Proteção Ambiental (APA).

Foram feitas duas visitas ao campo da pesquisa combinando diferentes técnicas de coleta de dados (EISENHARDT, 1989). Destacam-se nessa pesquisa o uso da análise documental, observação direta, entrevistas com roteiro semiestruturado (CRESWELL, 2010; EISENHARDT, 1989; YIN, 2015) e realização de 2 oficinas de AIS (ALEDO; GARCÍAANDREU; PINESE, 2015). Em agosto de 2018 foi realizada a observação direta na empresa e na comunidade vizinha ao projeto, as entrevistas com roteiros semiestruturados e a oficina com funcionários da organização. Em novembro e dezembro de 2018 foram conduzidas as entrevistas semiestruturadas e desenvolvida a oficina com moradores da comunidade vizinha ao projeto.

A análise documental teve como objetivo entender o contexto histórico, político, social e econômico do município e da região onde está instalado o empreendimento mineral, além de levantar dados sobre o processo de extração do minério. A análise incluiu elementos internos da empresa (CRESWELL, 2010), como relatórios de Sustentabilidade, Relatórios de Desempenho Ambiental, Sistema de Gestão de Stakeholder e documentos públicos de múltiplas fontes detalhadas no quadro 2. A observação direta foi realizada na primeira ida a campo durante visita à mina e ao centro de operações para acompanhamento presencial e melhor compreensão do processo produtivo a ser investigado. Também foi realizada visita à comunidade vizinha à operação mineral com o intuito de se aproximar e obter uma visão geral da localidade impactada pelo projeto e ao município. 
Quadro 2 - Descrição e origem das fontes secundárias de dados

\begin{tabular}{|c|c|c|}
\hline Tipos de documentos & Fonte & Informação aportada \\
\hline Relatórios sustentabilidade & Empresa & $\begin{array}{l}\text { Histórico de evolução da } \\
\text { mineradora na cidade }\end{array}$ \\
\hline Relatório de desempenho ambiental & Empresa & $\begin{array}{l}\text { Projetos desenvolvidos pela } \\
\text { mineradora na cidade no âmbito } \\
\text { ambiental }\end{array}$ \\
\hline Sistema de Gestão de Stakeholders & Empresa & $\begin{array}{l}\text { Mapeamento inicial de atores } \\
\text { importantes na cidade. Base para } \\
\text { criação da lista de entrevistados } \\
\text { pela pesquisa. }\end{array}$ \\
\hline $\begin{array}{l}\text { Relatórios da Secretária de Assistência } \\
\text { Social }\end{array}$ & Prefeitura & Histórico de formação da cidade \\
\hline $\begin{array}{l}\text { Diagnósticos Socioeconômicos e } \\
\text { Ambientais da região }\end{array}$ & Governo Estadual & $\begin{array}{l}\text { Caracterização socioeconômica e } \\
\text { ambiental da região }\end{array}$ \\
\hline Relatório de estatísticas municipais & Governo Estadual & $\begin{array}{l}\text { Dados demográficos, sociais e } \\
\text { econômicos da cidade }\end{array}$ \\
\hline $\begin{array}{l}\text { Relatório de caracterização } \\
\text { socioeconômica do município }\end{array}$ & $\begin{array}{l}\text { Ministério do Meio } \\
\text { Ambiente }\end{array}$ & $\begin{array}{l}\text { Caracterização geral, estrutura } \\
\text { fundiária e ordenação do solo }\end{array}$ \\
\hline Plano Nacional de Mineração 2030 & $\begin{array}{l}\text { Ministério de Minas e } \\
\text { Energia }\end{array}$ & $\begin{array}{l}\text { Contexto geral e previsão futura } \\
\text { para o cenário mineral no país }\end{array}$ \\
\hline Estatísticas IBGE & Governo Federal & $\begin{array}{l}\text { Dados demográficos, sociais e } \\
\text { econômicos da cidade }\end{array}$ \\
\hline Relatórios de Insustentabilidade & Movimento Social & $\begin{array}{l}\text { Principais críticas direcionadas à } \\
\text { empresa pela sociedade civil } \\
\text { organizada }\end{array}$ \\
\hline
\end{tabular}

Fonte: elaboração própria

A realização das entrevistas teve como ponto inicial a identificação e análise dos diferentes atores sociais que poderiam contribuir para a compreensão dos impactos. Partiu-se do sistema de gestão de stakeholders da empresa, publicações em periódicos regionais e indicações trazidas via snowball (GOODMAN, 1960), considerando o posicionamento frente ao projeto de mineração (ALEDO; DOMÍNGUEZ-GÓMEZ, 2018); poder de influência e legitimidade na comunidade (MITCHELL; AGLE; WOOD, 1997).

Foram desenvolvidos três tipos de questionários conforme descrito no quadro $3 . \mathrm{O} 1^{\circ}$ bloco de entrevistas se deu com gerentes da empresa e visou complementar as informações preliminares coletadas em dados secundários buscando conhecer o processo operacional e sua evolução. O $2^{\circ}$ bloco envolveu as organizações relevantes que atuam no município, o objetivo foi captar de maneira ampla a situação da cidade a fim de complementar dados secundários sobre o contexto institucional e político da região. $\mathrm{O} 3^{\circ}$ bloco visou à compreensão da trajetória de vida e teve como foco antigos moradores da comunidade a fim de ter uma prospecção longitudinal dos impactos advindos da mineração. Os três blocos desenvolvidos totalizaram14 entrevistas incluindo representantes da Empresas de mineração (E1), Moradores da comunidade (M1; M8), e atores externos pertencentes a organizações relevantes do município que auxiliaram no entendimento do contexto (A1). As entrevistas foram gravadas e posteriormente 
transcritas. As entrevistas geraram uma lista preliminar de impactos sociais que foram posteriormente trabalhados nas oficinas desenvolvidas na empresa e na comunidade local.

Quadro 3 - Descrição dos blocos de entrevistas realizadas para a coleta de dados primários

\begin{tabular}{|c|c|c|c|}
\hline Bloco de entrevistas & Objetivo & Entrevistados & Quantidade \\
\hline $1^{\circ}$ bloco de entrevistas & $\begin{array}{l}\text { Conhecer o processo } \\
\text { operacional e sua } \\
\text { evolução. }\end{array}$ & $\begin{array}{l}\text { Gerentes locais da } \\
\text { mineradora }\end{array}$ & 02 \\
\hline $2^{\circ}$ bloco de entrevistas & $\begin{array}{l}\text { Compreender o contexto } \\
\text { institucional e político da } \\
\text { região }\end{array}$ & $\begin{array}{l}\text { Pesquisadores, } \\
\text { empresários e } \\
\text { representantes de } \\
\text { movimentos sociais da } \\
\text { região }\end{array}$ & 04 \\
\hline $3^{\circ}$ bloco de entrevistas & $\begin{array}{l}\text { Ter uma prospecção } \\
\text { longitudinal dos } \\
\text { impactos advindos da } \\
\text { mineração }\end{array}$ & $\begin{array}{l}\text { Moradores da } \\
\text { comunidade vizinha à } \\
\text { operação da mineradora }\end{array}$ & 08 \\
\hline Oficina 01 & $\begin{array}{l}\text { Levantar e qualificar os } \\
\text { impactos levantados pela } \\
\text { empresa pelos } \\
\text { funcionários da empresa }\end{array}$ & $\begin{array}{l}\text { Funcionários de nível } \\
\text { operacional e de } \\
\text { diferentes gerencias da } \\
\text { mineradora }\end{array}$ & 12 \\
\hline Oficina 02 & $\begin{array}{l}\text { Qualificação dos } \\
\text { impactos levantados pela } \\
\text { comunidade durante as } \\
\text { entrevistas }\end{array}$ & Moradores da região & 06 \\
\hline
\end{tabular}

Fonte: elaboração própria

Os impactos levantados nas entrevistas foram agrupados a partir das categorias de Mancini e Sala (2018) e então levados para as oficinas que foram desenvolvidas adotaram o modelo proposto por Aledo e Domínguez-Gómez (2018) de forma a identificar os impactos mais relevantes na perspectiva da empresa e da comunidade bem como qualificá-los.

\subsection{Análise dos dados}

No processo de análise dos dados, os impactos classificados nas oficinas foram analisados de maneira a encontrar descrições semelhantes de ambos os atores. Foram agrupados em subgrupos dentro das categorias de Mancini e Sala (2018) os impactos que tratavam sobre um mesmo tema e então analisados de maneira a comparar as percepções da empresa e da comunidade com base na classificação realizada durante as oficinas e com o background 
fornecido pelas entrevistas individuais realizadas.

Em seguida foi feita a análise comparativa dos impactos que foram levantados pela comunidade, mas não foram considerados pela empresa e vice-versa. Por fim, por meio da análise de conteúdo das entrevistas extraiu-se trechos que ilustram as qualificações e relações causais dos impactos, permitindo a compreensão mais profunda das percepções.

\section{ANÁLISE E DISCUSSÃO DOS RESULTADOS}

$\mathrm{Na}$ análise comparativa entre os impactos identificados pela comunidade e empresa, identificou-se um conjunto de impactos comuns na visão da empresa e da comunidade, impactos distintos e sua respectiva qualificação como positivo ou negativo conforme Quadro 4.

Quadro 4 - Agrupamento e qualificação dos impactos levantados pela empresa e comunidade nas categorias "economia, renda e proteção" e "uso da terra e aspectos territoriais".

\begin{tabular}{|c|c|c|c|c|c|}
\hline \multirow[t]{8}{*}{$\begin{array}{l}\text { Categoria } \\
\text { Mancini \& } \\
\text { Sala (2018) }\end{array}$} & $\begin{array}{l}\text { Agrupamento } \\
\text { impacto }\end{array}$ & Impactos levantados & Empresa & Comunidade & $\begin{array}{l}\text { Quali } \\
\text { (a) }\end{array}$ \\
\hline & & $\begin{array}{l}\text { Diminuição de mercado dos produtos } \\
\text { agrícolas da comunidade }\end{array}$ & & $\mathrm{X}$ & $\mathrm{N}$ \\
\hline & Agricultura & Desestimulo dos agricultores & & $\mathrm{X}$ & $\mathrm{N}$ \\
\hline & & Queda na produção agrícola & $\mathrm{X}$ & $\mathrm{X}$ & $\mathrm{N}$ \\
\hline & Desenvolvim & $\begin{array}{l}\text { Empresa contribui para o desenvolvimento } \\
\text { econômico da cidade }\end{array}$ & $\mathrm{X}$ & $\mathrm{X}$ & $\mathrm{P}$ \\
\hline & $\begin{array}{l}\text { ento } \\
\text { econômico }\end{array}$ & $\begin{array}{l}\text { Desenvolvimento econômico do município é } \\
\text { dependente da operação da empresa }\end{array}$ & $\mathrm{X}$ & & $\mathrm{N}$ \\
\hline & Diálogo & Diálogo aumentou e melhorou & $\mathrm{X}$ & $\mathrm{X}$ & $\mathrm{P}$ \\
\hline & & $\begin{array}{l}\text { Ajuda o comercio local da comunidade - } \\
\text { projetos sociais da empresa }\end{array}$ & & $\mathrm{X}$ & $\mathrm{P}$ \\
\hline \multirow{9}{*}{$\begin{array}{c}\text { Economia, } \\
\text { renda e } \\
\text { proteção }\end{array}$} & & $\begin{array}{l}\text { Diversificação da produção - projetos sociais } \\
\text { da empresa }\end{array}$ & & $\mathrm{X}$ & $\mathrm{P}$ \\
\hline & & $\begin{array}{l}\text { Projetos sociais não atendem as demandas } \\
\text { locais }\end{array}$ & $\mathrm{X}$ & $\mathrm{X}$ & $\mathrm{N}$ \\
\hline & & $\begin{array}{l}\text { Aumento da produção - projetos sociais da } \\
\text { empresa }\end{array}$ & & $\mathrm{X}$ & $\mathrm{P}$ \\
\hline & $\begin{array}{l}\text { Projetos } \\
\text { sociais }\end{array}$ & $\begin{array}{l}\text { Demora no repasse dos recursos - projetos } \\
\text { sociais da empresa }\end{array}$ & & $\mathrm{X}$ & $\mathrm{N}$ \\
\hline & & $\begin{array}{l}\text { Recursos são insuficientes - projetos sociais } \\
\text { da empresa }\end{array}$ & & $\mathrm{X}$ & $\mathrm{N}$ \\
\hline & & $\begin{array}{l}\text { Dificuldade de acesso ao mercado - projetos } \\
\text { sociais da empresa }\end{array}$ & & $\mathrm{X}$ & $\mathrm{N}$ \\
\hline & & $\begin{array}{l}\text { Não melhora a renda para todos os } \\
\text { beneficiários - projetos sociais da empresa }\end{array}$ & & $\mathrm{X}$ & $\mathrm{N}$ \\
\hline & & $\begin{array}{l}\text { Poucos beneficiários - projetos sociais da } \\
\text { empresa }\end{array}$ & & $\mathrm{X}$ & $\mathrm{N}$ \\
\hline & & & & $(\mathrm{CO}$ & NUA) \\
\hline
\end{tabular}




\begin{tabular}{|c|c|c|c|c|c|}
\hline & & Ausência do poder público para projetos & $\mathrm{X}$ & \multirow{3}{*}{$\mathrm{X}$} & $\mathrm{N}$ \\
\hline & & $\begin{array}{l}\text { Preconceito sofrido por participar de projetos } \\
\text { sociais da empresa }\end{array}$ & & & $\mathrm{N}$ \\
\hline & & Projetos sociais voluntários & $\mathrm{X}$ & & $\mathrm{P}$ \\
\hline & Insegurança & Medo de ser indenizado injustamente & & $\mathrm{X}$ & $\mathrm{N}$ \\
\hline & $\mathrm{C}_{-} \sim$ & $\begin{array}{l}\text { Suborno e corrupção por parte de } \\
\text { governantes e empreendedores }\end{array}$ & $\mathrm{X}$ & & $\mathrm{N}$ \\
\hline & Corrupçao & $\begin{array}{l}\text { Corrupção na região afeta reputação da } \\
\text { empresa }\end{array}$ & $\mathrm{X}$ & & $\mathrm{N}$ \\
\hline & Sopuranco & Aumento da criminalidade & $\mathrm{X}$ & & $\mathrm{N}$ \\
\hline & Segula ăça & Assédio aos funcionários & $\mathrm{X}$ & & $\mathrm{N}$ \\
\hline & & Desigualdade socioeconômica aumentou & $\mathrm{X}$ & & $\mathrm{N}$ \\
\hline & Renda & Diminuição da renda & & $\mathrm{X}$ & $\mathrm{N}$ \\
\hline & & $\begin{array}{l}\text { Geração de renda - projetos sociais da } \\
\text { empresa }\end{array}$ & & $\mathrm{X}$ & $\mathrm{P}$ \\
\hline & Cultural & $\begin{array}{l}\text { Dificuldade de adaptação dos jovens à vida } \\
\text { na cidade }\end{array}$ & & $\mathrm{X}$ & $\mathrm{N}$ \\
\hline \multirow{4}{*}{$\begin{array}{l}\text { Uso da terra } \\
\text { e aspectos } \\
\text { territoriais }\end{array}$} & Agricultura & $\begin{array}{l}\text { Não há produção local. Alimentos } \\
\text { consumidos no município vêm de outras } \\
\text { localidades }\end{array}$ & $\mathrm{X}$ & $\mathrm{X}$ & $\mathrm{N}$ \\
\hline & & Perda da tradição de cultura agrícola & & $\mathrm{X}$ & $\mathrm{N}$ \\
\hline & Infraestrutura & $\begin{array}{l}\text { Infraestrutura melhorou com ciclo de grandes } \\
\text { obras }\end{array}$ & $\mathrm{X}$ & & $\mathrm{P}$ \\
\hline & Insegurança & Insegurança sobre o território e o futuro & & $\mathrm{X}$ & $\mathrm{N}$ \\
\hline
\end{tabular}

Nota. (a) considera-se Qualificação: $\mathrm{P}=$ Positivo e $\mathrm{N}=$ Negativo

Fonte: elaboração própria

Com relação ao quadro apresentado, a primeira análise centrou-se na categoria "economia, renda e proteção", subgrupo "agricultura". Ela evidencia que a empresa descreve o impacto de maneira ressaltando os aspectos concretos que prejudicam a produção agrícola enquanto a comunidade dá ênfase a questões mais subjetivas e culturais. Assim para a empresa, uma das explicações para a queda da produção agrícola está nos problemas logísticos como ampliação e melhoria de estradas para escoamento de produção. Já o caráter subjetivo e cultural da perda de produção agrícola é reforçado pelas questões do desestímulo dos agricultores e a perda da tradição agrícola. Para tanto é preciso entender o processo e o contexto da ocupação do território (ALEDO; DOMÍNGUEZ-GÓMEZ, 2018).

A região começou a ser ocupada no início da década de 1980 com a chegada de famílias de colonos que buscavam novas possibilidades de geração de renda em projeto de assentamento rural. A comunidade tornou-se então a maior produtora de frutas da região fornecendo alimentos para subsistência e abastecendo o mercado local. A superação das dificuldades para desenvolver a produção nesta localidade, considerando a falta de tecnologia disponível, 
construiu um sentimento de coletividade entre os produtores. Tal sentimento foi se perdendo com o declínio da atividade agrícola e pode ser explicado por diversos fatores. $\mathrm{O}$ primeiro estaria ligado a um fenômeno já explorado na literatura referente a concorrência oferecida pela atividade de mineração em relação as ocupações tradicionais. Rosyida, Khan e Sasaoka (2018) mencionam a atração por empregos na mineração motivados por safras ruins ou para sustentar a renda familiar após o final da época agrícola.

O impacto maior em termos de redução ou estagnação foi do campo. O ponto negativo foi a saída de muita gente do campo (...) As mudanças que acompanhei aqui foi no campo, teve que ceder muita gente. Na verdade atraída por. ... é o sonho de trabalhar com uniforme (A1).

No território analisado há uma outra explicação fundamental que foi a transformação do território em Área de Proteção Ambiental - APA em 1989. Com isso houve a proibição das técnicas de cultivo originalmente utilizadas tais como queima e derrubada de vegetação. As técnicas tradicionais não foram substituídas por novas que garantissem o incremento da produção agrícola.

O pessoal tinha hábito de plantar a roça, queimar a roça para poder plantar. Dentro da área eles foram proibidos de fazer esse procedimento (M1).

Sobre o subgrupo "desenvolvimento econômico" ambas reconhecem o papel essencial da empresa no desenvolvimento do município. Na visão da comunidade, a chegada da empresa foi essencial para melhorar a infraestrutura de transportes e na saúde.

Há 09 anos as estradas eram muito difíceis. Demorava horas para chegar lá na comunidade, a Unidade de saúde funcionava a cada 3 meses. Atendiam até 100 pessoas por dia. Já não era nada bancado pela Prefeitura era tudo custeado pela empresa. Prefeitura não atuava lá, era só a empresa. A empresa fazia tudo (M2).

Já com relação ao subgrupo projetos sociais verifica-se uma profusão de pontos de vista positivos e negativos, especialmente na comunidade. Nas entrevistas realizadas, parte dos moradores reconhecem a contribuição dos projetos sociais da empresa na geração de emprego e melhoria na educação. No entanto, esta percepção divide espaço com uma visão também negativa destas iniciativas, tanto por parte da comunidade como da própria empresa. Entre as críticas da própria empresa, aparece que a iniciativa de projeto social - voltado a expandir a produção de leite e a implantar um laticínio para a venda de leite e queijos - pouco tem contribuído para a recuperação econômica. $\mathrm{Na}$ visão da própria empresa, o projeto apresenta baixa interação com a história do município.

Por conta do laticínio e desse projeto de leite, a gente tem uma condicionante ambiental que é reduzir a possibilidade de queimadas, e desde lá de trás nós temos trabalhado 
isso com mecanização, ao invés de queimada, mudando a prática para a ocupação, na melhoria dessas áreas como áreas agrícolas. E uma coisa que é meio que aos trancos e barrancos é a questão do leite, eles gostam de frutas (E1).

A conjunção destes fatores culminou em uma situação em que não foi possível diversificar a produção, resultando na perda da autossuficiência da produção agrícola. Kotey; Rolfe (2014) argumentam que em áreas remotas, onde há comunidade vizinha a mineração, existe maior dificuldade na diversificação da produção, fator observado também no caso analisado. Um problema vivido hoje pela comunidade é a necessidade de importar alimentos de outras regiões que surgem como um impacto indireto conforme descrito por Vanclay (2002).

Focando nos impactos distintos levantados pela empresa e comunidade na categoria "economia, renda e proteção", observa-se que os impactos indicados pela comunidade detalham mais as causas dos problemas enfrentados pelos "projetos sociais" já mencionados anteriormente. A insuficiência de recursos, a demora no repasse dos mesmos não condiz com a realidade da lavoura ou da criação e a dificuldade de acesso ao mercado dos produtos cultivados são destacados pelos entrevistados.

Recebemos um gado de leite de um projeto da empresa, mas não teve qualidade (...) As vaquinhas já vieram doente (...) e não terminaram nos curais de todo mundo. As partes que ela promete ela não faz o compromisso de obedecer, nós somos vizinhos, nós obedecemos, não botamos fogo em nada e ela prometeu que dava essas horas de máquina para ajudar a fazer a roça, dava as pessoas para acompanhar o plantio, assistência técnica (M3).

Tal percepção da empresa remete ao que é trazido por Esteves, et al. (2017), a comunidade tolera a distribuição dos riscos negativos se os positivos forem igualmente distribuídos. A comunidade ainda indica um impacto não encontrado na revisão da literatura. O preconceito que sofrem pela sua área ser beneficiária de diversos projetos sociais da empresa. Para os entrevistados nesta pesquisa o restante da cidade os vê como privilegiados, pois recebem muita ajuda da empresa por meio do projetos sociais desenvolvidos na comunidade. Já a percepção da empresa dos problemas aparece em fatores externos aos seus projetos, como a ausência do poder público e "corrupção". Ela afirma que a corrupção na região afeta sua reputação e a omissão da gestão pública faz com que recaia sobre ela uma série de demandas que não deveriam lhe ser atribuídas. Nesse sentido, alguns dos impactos indicados na oficina com a empresa corrobora Barclay, Franks e Pettenden (2009) de uma visão de riscos e impactos para o negócio e em detrimento dos riscos para a comunidade.

Seguindo no tema da "proteção", menciona-se o assédio constante aos funcionários. Eles são também moradores da cidade e das comunidades e acabam sempre sendo demandados 
e questionados mesmo em suas horas de folga e laser. Chama a atenção o fato de a comunidade não listar nenhum impacto envolvendo diretamente a gestão pública. $\mathrm{O}$ mesmo acontece em relação à proteção quando apenas a empresa percebe o aumento da criminalidade no município.

A relação de dependência econômica das regiões e municípios que concentram operações minerais (ATIENZA; LUFIN; SOTO, 2018), acentuada pela incapacidade do governo e empresas em oferecer estratégias e oportunidades de subsistência a longo prazo para os residentes (BRAIN, 2017), é bem documentada na literatura. Mas no caso analisado e relacionado à categoria de "uso da terra e aspectos territoriais", percebe-se como a questão de dependência extrema da empresa reforça uma visão que acaba excluindo o poder municipal de sua responsabilidade na construção de um futuro para o território. A perda do sentimento de coletividade construído no início do processo de colonização pode ser vista no impacto "insegurança" sobre o futuro do território quando a comunidade menciona seu medo de ser indenizado injustamente ou da utilização de um novo rio para fins de extração de minério pela empresa.

Eu não sei se atrapalha ou ajuda, mas nós esperamos que um dia a empresa vai entrar assim com uma negociação para nós (...) Que o dia que ela precisar ela vem aqui e fala: você arruma a bagagem aí que a área é realmente nossa (...) Aqui é cheio de minério (...) Se Deus abençoar, tocar o coração que eles indenizem com um valor que a gente possa viver uma vida mais legal, tudo bem, mas se der só uma merrequinha nós vamos sofrer de novo (M3).

A gente preocupa futuramente né? Se ela precisar desse rio aí. Que nem ela precisou do outro lá da barragem. E ela só vem descendo, descendo... então é lógico que daqui dez anos, vinte anos ela vai precisar desse outro (M8).

Quadro 5 - Agrupamento e qualificação dos impactos levantados pela empresa e comunidade na categoria "emprego e educação".

\begin{tabular}{|c|c|c|c|c|c|}
\hline $\begin{array}{l}\text { Categoria } \\
\text { Mancini \& } \\
\text { Sala (2018) }\end{array}$ & $\begin{array}{l}\text { Agrupamento } \\
\text { impacto }\end{array}$ & Impactos levantados & Empresa & Comunidade & $\begin{array}{l}\text { Quali } \\
\text { (a) }\end{array}$ \\
\hline \multirow{9}{*}{$\begin{array}{c}\text { Emprego } \\
\text { e } \\
\text { educação }\end{array}$} & \multirow{3}{*}{ Desemprego } & Desemprego na comunidade & & $\mathrm{X}$ & $\mathrm{N}$ \\
\hline & & $\begin{array}{l}\text { Geração de empregos diretos e indiretos - } \\
\text { projetos sociais da empresa }\end{array}$ & & $\mathrm{X}$ & $\mathrm{P}$ \\
\hline & & Aumento do desemprego & $\mathrm{X}$ & & $\mathrm{N}$ \\
\hline & \multirow{3}{*}{ Escolas } & Infraestrutura escolar melhorou no município & & & $\mathrm{P}$ \\
\hline & & $\begin{array}{l}\text { Melhora na qualidade das escolas da } \\
\text { comunidade }\end{array}$ & & & $\mathrm{P}$ \\
\hline & & Educação de baixa qualidade & $\mathrm{X}$ & & $\mathrm{N}$ \\
\hline & \multirow{3}{*}{ Trabalho } & Redução de trabalho infantil & $\mathrm{X}$ & & $\mathrm{P}$ \\
\hline & & Oferta de cursos de formação & $\mathrm{X}$ & & $\mathrm{P}$ \\
\hline & & $\begin{array}{l}\text { Baixa qualidade dos serviços oferecidos no } \\
\text { município }\end{array}$ & $\mathrm{X}$ & & $\mathrm{N}$ \\
\hline
\end{tabular}


Nota. (a) considera-se Qualificação: $\mathrm{P}=$ Positivo e $\mathrm{N}=$ Negativo

Fonte: elaboração própria

Na categoria de "emprego e educação" há também uma concordância em relação ao desemprego. A empresa dá grande ênfase à questão do desemprego, considerando-o a fonte de outros impactos e do aumento de conflitos com a comunidade local. Na sua percepção, enquanto a mineradora ofertava emprego, os outros impactos não geravam conflitos altos entre comunidade e empresa. No que se refere especificamente a questão educacional, a comunidade percebe uma melhoria na qualidade do ensino de base e das escolas de sua região e atribui esse avanço às ações da empresa.

Eram colégios bem menores (...) tinha três colégios, tirou todos os colégios daí né, colocou em um maior. E melhorou a qualidade era colégio ruim, colocou professor novo e melhor (M3).

Quadro 6 - Agrupamento e qualificação dos impactos levantados pela empresa e comunidade nas categorias "demográfica" e "direitos humanos"

\begin{tabular}{|c|c|c|c|c|c|}
\hline $\begin{array}{l}\text { Categoria } \\
\text { Mancini \& } \\
\text { Sala (2018) }\end{array}$ & $\begin{array}{l}\text { Agrupament } \\
\text { o impacto }\end{array}$ & Impactos levantados & Empresa & Comunidade & $\begin{array}{l}\text { Quali } \\
\text { (a) }\end{array}$ \\
\hline \multirow{3}{*}{$\begin{array}{l}\text { Demografi } \\
\text { a }\end{array}$} & \multirow{3}{*}{ Demografia } & Migração dos jovens & & $\mathrm{X}$ & $\mathrm{N}$ \\
\hline & & Envelhecimento da população & & $\mathrm{X}$ & $\mathrm{N}$ \\
\hline & & Crescimento populacional desordenado & $\mathrm{X}$ & & $\mathrm{N}$ \\
\hline \multirow{4}{*}{$\begin{array}{l}\text { Direitos } \\
\text { Humanos }\end{array}$} & Truculência & Segurança empresarial - abuso de poder & $\mathrm{X}$ & & $\mathrm{N}$ \\
\hline & \multirow{3}{*}{ Gestão } & $\begin{array}{l}\text { Segurança empresarial - abuso do poder } \\
\text { diminuiu }\end{array}$ & & $\mathrm{X}$ & $\mathrm{P}$ \\
\hline & & Não há evidências de abuso aos direitos humanos & $\mathrm{X}$ & & $\mathrm{P}$ \\
\hline & & Respeitam questões de gênero & $X$ & & $\mathrm{P}$ \\
\hline
\end{tabular}

Nota. (a) considera-se Qualificação: $\mathrm{P}=$ Positivo e $\mathrm{N}=$ Negativo

Fonte: elaboração própria

Já categoria Na questão "demográfica", mostram que a comunidade tem um entendimento mais amplo dos impactos ocorridos nos últimos anos. Enquanto para a empresa, problemas demográficos estão relacionados a um crescimento populacional desordenado, para a comunidade a migração de jovens aparece com principal problema, pois há grande preocupação com a dificuldade de adaptação do jovem na cidade e com o envelhecimento da população local. Além disso, nas entrevistas um impacto importante que não apareceu nos impactos levantados pela empresa foi a questão de a dificuldade da população mais jovem constituir família. Isto decorre do fato que a migração de jovens é principalmente feminina, já que os filhos acabam sofrendo uma maior pressão para ficar e trabalhar na propriedade familiar. Percebe-se que a comunidade se preocupa com os recursos culturais e com o bem-estar das pessoas, o que nem sempre está presente nos impactos listados pela empresa (SOLOMON; 


\section{KATZ; LOVEL, 2008).}

$\mathrm{Na}$ categoria de "direitos humanos" menciona-se a "truculência" da empresa terceirizada contatada para proteger a área. Nos últimos anos, no entanto, há um reconhecimento compartilhado pela comunidade de uma melhoria acentuada nesta relação a partir da substituição da empresa terceirizada. Além disso, percebem também uma melhoria do diálogo, provavelmente devido as estratégias de aproximação da empresa por meio da implantação de uma área de relacionamento com a comunidade com a responsabilidade exclusiva por fazer a ponte entre as comunidades e a empresa. Anteriormente muitas das atividades de interação com a comunidade eram feitas por funcionários terceirizados, muitas vezes associados pelos entrevistados aos colaboradores de segurança patrimonial.

É possível observar que a categoria "direitos humanos" é pouco percebida pela comunidade e mesmo pela empresa. Foram apenas dois impactos levantados pelos representantes da empresa e ambos indicados como positivos. Os impactos apresentados como positivos pela empresa na categoria "direitos humanos" são obrigações trabalhistas e remete a aspectos legais, não demostrando avanços significativos nessa questão.

Quadro 7 - Agrupamento e qualificação dos impactos levantados pela empresa e comunidade na categoria "meio ambiente, saúde e segurança".

\begin{tabular}{|c|c|c|c|c|c|}
\hline \multirow[t]{6}{*}{$\begin{array}{c}\text { Categoria } \\
\text { Mancini \& } \\
\text { Sala (2018) }\end{array}$} & $\begin{array}{l}\text { Agrupamento } \\
\text { impacto }\end{array}$ & Impactos levantados & Empresa & Comunidade & $\begin{array}{l}\text { Quali } \\
\text { (a) }\end{array}$ \\
\hline & \multirow{5}{*}{$\begin{array}{l}\text { Qualidade da } \\
\text { água }\end{array}$} & Alteração na turbidez da água & $\mathrm{X}$ & & $\mathrm{N}$ \\
\hline & & $\begin{array}{l}\text { Problemas de saúde relacionados ao consumo } \\
\text { da água }\end{array}$ & & $\mathrm{X}$ & $\mathrm{N}$ \\
\hline & & Alta concentração de minério na água & & $\mathrm{X}$ & $\mathrm{N}$ \\
\hline & & Contaminação dos peixes & & $\mathrm{X}$ & $\mathrm{N}$ \\
\hline & & $\begin{array}{l}\text { Necessidade de cavar poço artesiano ou } \\
\text { comprar água }\end{array}$ & & $\mathrm{X}$ & $\mathrm{N}$ \\
\hline \multirow{7}{*}{$\begin{array}{c}\text { Meio } \\
\text { Ambiente, } \\
\text { Saúde e } \\
\text { Segurança }\end{array}$} & \multirow{3}{*}{$\begin{array}{l}\text { Qualidade do } \\
\quad \text { ar }\end{array}$} & Combustível fóssil - Mina & $\mathrm{X}$ & & $\mathrm{N}$ \\
\hline & & $\begin{array}{l}\text { Combustível fóssil - transporte de } \\
\text { funcionários }\end{array}$ & $\mathrm{X}$ & & $\mathrm{N}$ \\
\hline & & Poeira e particulado - Mina & $\mathrm{X}$ & $\mathrm{X}$ & $\mathrm{N}$ \\
\hline & \multirow{4}{*}{$\begin{array}{l}\text { Desflorestam } \\
\quad \text { ento }\end{array}$} & Desflorestamento - ambiental & $\mathrm{X}$ & $\mathrm{X}$ & $\mathrm{N}$ \\
\hline & & Desflorestamento - econômico e social & $\mathrm{X}$ & & $\mathrm{N}$ \\
\hline & & Desflorestamento - incêndio & $\mathrm{X}$ & & $\mathrm{N}$ \\
\hline & & Assoreamento da barragem & & $\mathrm{X}$ & $\mathrm{N}$ \\
\hline
\end{tabular}




\begin{tabular}{|c|c|c|c|c|}
\hline \multicolumn{5}{|l|}{ (CONTINUAÇÃO) } \\
\hline $\begin{array}{l}\text { Rompimento } \\
\text { barragem }\end{array}$ & $\begin{array}{l}\text { Percepção de risco pela empresa e medo do } \\
\text { rompimento da barragem pela comunidade }\end{array}$ & $\mathrm{X}$ & $\mathrm{X}$ & $\mathrm{N}$ \\
\hline \multirow[b]{2}{*}{ Proteção } & Comunidade tem papel na proteção da APA & & $\mathrm{X}$ & $\mathrm{P}$ \\
\hline & $\begin{array}{l}\text { Segurança empresarial e guarda florestal - } \\
\text { segurança da unidade de conservação }\end{array}$ & $\mathrm{X}$ & & $\mathrm{P}$ \\
\hline & Contaminação do solo & & $\mathrm{X}$ & $\mathrm{N}$ \\
\hline Água & Aumento da oferta de água & $\mathrm{X}$ & & $\mathrm{P}$ \\
\hline Insegurança & $\begin{array}{l}\text { Medo da futura utilização um novo rio pela } \\
\text { empresa }\end{array}$ & & $\mathrm{X}$ & $\mathrm{N}$ \\
\hline Segurança & $\begin{array}{l}\text { Percepção de risco de afogamento na } \\
\text { barragem }\end{array}$ & $\mathrm{X}$ & & $\mathrm{N}$ \\
\hline
\end{tabular}

Nota. (a) considera-se Qualificação: $\mathrm{P}=$ Positivo e $\mathrm{N}=$ Negativo

Fonte: elaboração própria

A categoria de "meio ambiente, saúde e segurança" traz impactos pertencentes a qualidade da água, ar, desflorestamento e rompimento da barragem. Aspectos relativos à água, foram muito valorizadas pela comunidade local que conta com um convívio direto com recursos hídricos em seu território, estando em uma área rural e de proteção ambiental sua proximidade e dependência do rio é elevada o que faz com que a comunidade consiga descrever os efeitos diretos da perda da qualidade da água.

Eu tinha uns tanques de peixe lá em casa. A água entrou dentro dos meus tanques e matou tudo quanto foi peixe que tinha lá dentro (...) Maioria do pessoal não bebe mais dessa água (M4).

A empresa por sua vez tem o foco nos parâmetros legais da "qualidade da água". Assim reconhece como único impacto o processo de turbidez. Mas mesmo neste caso argumenta que a mudança na qualidade da água está de acordo com os padrões legais, excluindo-se de qualquer responsabilidade de eventual contaminação na água. Já o órgão ambiental responsável pela área atribui o processo de contaminação da água à presença de garimpeiros ilegais na região. São pessoas que vão para o município para trabalhar nas obras dos projetos de mineração da empresa e no fim dessas obras quando se veem desempregados procuram outras ocupações, sendo o garimpo ilegal uma opção. Apesar da comunidade reconhecer também o papel do garimpeiro ilegal na contaminação da água, acredita que o minério sedimentado, gerado no processo produtivo da mineradora, impacta a qualidade da água. Dessa forma apontam a empresa como a principal responsável na medida em que é a gestora da barragem e indiretamente responsável pela presença de garimpo ilegal na área. 
Com relação aos impactos na "qualidade do ar", a empresa indica apenas aqueles que são provenientes das atividades desenvolvidas na mina, restringindo os impactos aos seus funcionários. Além disso, alegam que pelo fato de a mina estar rodeada de vegetação os incômodos de particulados da mina não chegam até a comunidade. A comunidade, entretanto, relata impactos diretos e cotidianos relativos ao ar.

A poeira incomoda um pouco, mas é mais as crianças por questão respiratória, eu acho que é por causa da poeira. Aqui a gente não percebe muito, mas chega. Agora lá no outro lado da comunidade tem até tempestade de poeira, fica tudo vermelho assim, quando eles soltam aquelas bombas. Cobre tudo, tudo por lá (M5).

De maneira semelhante ao observado no subgrupo "qualidade do ar" 0 "desflorestamento" é mais detalhado pela empresa do que pela comunidade local, entretanto foca nos aspectos ambientais do desmatamento enquanto a comunidade fala dos impactos sociais dele advindos. Exemplo é o deslocamento de pássaros do entorno da represa para as lavouras, prejudicado a produção dos agricultores da comunidade.

Com o assoreamento o maior impacto foi o grande fluxo de animais. A mata era em grande extensão e quando a empresa levantou 14 metros de lâmina de água para aumentar a barragem, a mata foi devastada. Então diminuiu a mata e quando diminui a mata as aves vêm buscar alimento nas áreas dos produtores. Come a roça inteira (M6).

Outra questão listada pela comunidade que perpassa o "desflorestamento" é o conflito gerado a partir da discrepância de direitos entre a comunidade e a empresa. Enquanto a empresa consegue autorizações para desflorestamento dentro da APA, para construção de energia e outros processos decorrentes da atividade de mineração que demandam desflorestamento, o pequeno produtor rural não consegue autorização para aumentar sua área de cultivo dentro de seu próprio quintal.

Não tem mais onde plantar na comunidade. Para plantar tem que desmatar. Não produz o suficiente (...) porque a terra está cansada, tem que abrir outra área nova. Por que a empresa pode abrir áreas novas e o produtor não pode? (M2).

Sobre a questão relativa à possibilidade de "rompimento da barragem", a empresa indica como impacto o risco do rompimento da barragem enfatizando o viés de risco para o negócio (KEMP; WORDEN; OWEN, 2016), já no ponto de vista da comunidade o impacto já existe uma vez que o medo já se configura como o impacto em si. 
Na associação fizeram uma reunião e disseram que nunca vai acontecer da barragem estourar, mas eu tenho medo (...) Dai eles falaram que tem a sirene, dá para ouvir a sirene daqui, e os empregados da empresa falam que tem que pegar o carro, deixar o que tiver e saí correndo. E eu disse - E as minhas galinhas? E meus cachorros? E minhas vacas? (M7).

Ainda na categoria de "meio ambiente, saúde e segurança" tanto a empresa quanto a comunidade mencionam o aspecto de proteção da área. A comunidade considera-se agente de proteção da área e sente que está prestando um serviço indireto para a empresa à medida que está colaborando para evitar ocupações ilegais. Já a empresa relaciona esse aspecto exclusivamente aos serviços de segurança empresarial que contrata.

Um ponto bastante relevante que separa a visão da empresa da comunidade é em relação à oferta da água. Como comentado, a água é um fator de grande preocupação na comunidade. Sua percepção do processo de contaminação fez com que buscassem alternativas como poços artesianos para consumo. No entanto, a empresa defende que o processo de mineração aumenta a disponibilidade de água. A empresa indicou ainda a percepção do risco de afogamento na barragem, enquanto a comunidade destaca nas entrevistas que a atividade de lazer no rio foi impactada com a construção da represa. Para a empresa, o risco está na possibilidade de afogamento e nos impactos associados ao evento, incluindo o reputacional e a responsabilização legal, enfatizando a percepção do risco para o negócio.

\section{CONSIDERAÇÕES FINAIS}

O debate sobre a identificação e gestão de impactos sociais avança para a necessidade de uma integração entre o enfoque técnico-científico e o construtivista e participativo, de forma a compreender o fenômeno em sua amplitude. A pesquisa realizada mostrou convergência com a literatura no que se refere aos impactos identificados pela empresa e comunidade, excluindose a categoria "meio ambiente, saúde e segurança". A pesquisa de campo reforça o peso dos impactos ambientais negativos como uma das principais consequências de um projeto mineral. Nesse caso, a empresa e a comunidade se aproximam na percepção. Diferentemente de Mancini e Sala (2018), a variedade de impactos negativos levantados pelos atores entrevistados reforça a importância do contexto local na ressignificação dos impactos. Infere-se que a relevância dada pela comunidade à categoria de "meio ambiente, saúde e segurança" relaciona-se ao fato de a comunidade analisada situar-se em contexto rural. Com um histórico de formação ligado a projetos de assentamento rural, os entrevistados reforçaram o aspecto de que a qualidade 
ambiental do território é uma condição direta para sua subsistência. Assim, a contaminação dos peixes emerge como um impacto negativo relevante não identificado na categorização proposta por Mancini e Sala (2018). Também a questão da segurança de barragens, um problema central no debate atual sobre mineração no país, aponta novas variáveis a serem incorporadas no que se refere aos impactos sociais de projetos de mineração. Destaca-se ainda que o fato da empresa identificar os impactos ambientais em um número maior do que qualquer outra categoria, reforça a familiaridade de gestores e técnicos com as variáveis ambientais, sendo necessário avançar na compressão de impactos menos discutidos no contexto brasileiro como demografia, direitos humanos e uso da terra.

Especificamente no que se refere à questão central desta pesquisa, de como a percepção de empresa e comunidade sobre impactos de projetos de mineração influencia o processo de identificar e priorizar impactos, verificou-se que a metodologia utilizada pode contribuir para esta visão ampliada do processo. Verificou-se no trabalho de campo que empresa e comunidade compartilham um grande número de impactos, especialmente a contribuição econômica da atividade para o território, melhorias de infraestrutura na educação e na saúde e o diálogo entre a empresa e a comunidade. No entanto, em diversos impactos identificados, verificam-se entendimentos e explicações bastante distintos.

Observa-se que, no processo de seleção de impactos, a empresa foca nos mais imediatos, muitas vezes com viés dos riscos para o negócio, associados à ausência e ineficiência do poder público em apoiar projetos de desenvolvimento local. Já o olhar da comunidade avança para além da questão dos impactos mais imediatos como oferta e qualidade da água e queda produção agrícola. Sem desconsiderar variáveis, pontuam questões subjetivas e culturais associadas aos processos de mudança. Sem o real entendimento destes processos, infere-se que as mudanças na forma de vida e nas tradições fragilizam estratégias compensatórias como o projeto social implementado, pois questões mais profundas associadas aos impactos não são endereçadas como a perda do sentimento de coletividade e o impacto do processo migratório no esgarçamento dos laços familiares. Dessa forma, o grande desafio está em migrar de projetos sociais frágeis e pontuais para projetos estruturantes, de longo prazo e que visem ao desenvolvimento local em compartilhamento com o poder público, tema que poderia ser considerado e aprofundado em estudos futuros.

Nesse sentido, considerando as limitações inerentes à realização de estudos de casos únicos, argumenta-se que o uso da metodologia AIS aqui apresentada representa uma contribuição das ciências sociais em ampliar os processos de avaliação de riscos e impactos. 
Há implicações práticas também na medida em que a metodologia proporciona à empresa uma abordagem analítica diferenciada para a gestão dos seus impactos e dá voz às comunidades sobre como os processos de mudança social são por elas percebidos e sentidos. Particularmente no caso brasileiro, considerando as recentes tragédias socioambientais envolvendo o setor de mineração, o avanço teórico e prático desta metodologia pode representar uma importante contribuição para reduzir impactos econômicos, ambientais e sociais.

Ressalta-se, por fim, a importância da AIS nas diferentes fases de vida do projeto de mineração. Ainda que o estudo de caso aqui desenvolvido foque em um projeto de mineração em fase de operação, é importante desenvolver estudos futuros que investiguem as percepções dos atores envolvidos nas diferentes fases de um projeto de mineração, desde sua prospecção até o encerramento. É importante ainda que a pesquisa expanda sua abrangência de análise incluindo mais comunidades de forma a abarcar também o contexto urbano, ampliando o entendimento dos impactos gerados por projetos minerários.

\section{AGRADECIMENTO}

Agradecemos à Gerência de Tecnologia, Inovação e Sustentabilidade da Vale pelo apoio a este projeto de pesquisa.

\section{REFERÊNCIAS}

ALEDO, A.; DOMÍNGUEZ-GÓMEZ, J. A. Evaluación de impacto social: teoría, método y casos prácticos. 1. ed. Alicante: Universidad de Alicante, 2018.

ALEDO, A.; GARCÍA-ANDREU, H.; PINESE, J. Using causal maps to support ex-post assessment of social impacts of dams. Environmental Impact Assessment Review, v. 55, p. 84-97, 2015.

ATIENZA, M.; LUFIN, M.; SOTO, J. Mining linkages in the Chilean copper suplly network and regional economic development. Resources Policy, 2018.

BARCLAY, M. A.; FRANKS, D. M.; PETTENDEN, C. Risk communication: A framework for technology development and implementation in the mining and minerals processing industries: Final report. Australia, 2009.

BRAIN, K. A. The impacts of mining on livelihoods in the Andes: A critical overview. The Extractive Industries and Society, v. 4, p. 410-418, 2017. 
CLIMENT-GIL, E.; ALEDO, A.; VALLEJOS-ROMERO, A. The social vulnerability approach for social impact assessment. Environmental Impact Assessment Review, v. 73, n. April, p. 70-79, 2018.

CRESWELL, J. W. Projeto de pesquisa: métodos qualitativo, quantitativo e misto. 2. ed. Porto Alegre: Artmed, 2010.

EISENHARDT, K. M. Building Theories from Case Study Research. Academy of Management Review, v. 14, n. 4, p. 532-550, 1989. Disponível em: <http://journals. aom.org/doi/10.5465/amr.1989.4308385>.

ESTEVES, A. M. et al. Adapting social impact assessment to address a project's human rights impacts and risks. Environmental Impact Assessment Review, v. 67, n. January, p. 73-87, 2017.

ESTEVES, A. M.; FRANKS, D.; VANCLAY, F. Social impact assessment: the state of the art. Impact Assessment and Project Appraisal, v. 30, n. 1, p. 34-42, 2012.

ESTEVES, A. M.; VANCLAY, F. Social Development Needs Analysis as a tool for SIA to guide corporate-community investment: Applications in the minerals industry. Environmental Impact Assessment Review, v. 29, n. 2, p. 137-145, 2009.

FOO, N.; BLOCK, H.; SALIM, R. The optimisation rule for investment in mining projects. Resources Policy, v. 55, p. 123-132, 2018

FRANKS, D. M.; BRERETON, D.; MORAN, C. J. The cumulative dimensions of impact in resource regions. Resources Policy, v. 38, n. 4, p. 640-647, 2013.

FRANKS, D. M. et al. Conflict translates environmental and social risk into business costs. Proceedings of the National Academy of Sciences, v. 111, n. 21, p. 7576-7581, 2014.

FRANKS, D. M.; VANCLAY, F. Social Impact Management Plans: Innovation in corporate and public policy. Environmental Impact Assessment Review, v. 43, p. 40-48, 2013.

GOODMAN, L. A. Snowball Sampling. The Annals of Mathematical Statistics, p. 148-170, 1960 .

HANSEN, A. M. et al. Managing the social impacts of the rapidly-expanding extractive industries in greenland. Extractive Industries and Society, v. 3, n. 1, p. 25-33, 2016.

HARVEY, B.; BICE, S. Social impact assessment, social development programmes and social licence to operate: Tensions and contradictions in intent and practice in the extractive sector. Impact Assessment and Project Appraisal, v. 32, n. 4, p. 327-335, 2014.

JOYCE, S. A.; MACFARLANE, M. Social Impact Assessment in the Mining Industry: Current Situation and Future Directions. Mining Minerals and Sustainable Development, 2001.

KEMP, D.; WORDEN, S.; OWEN, J. R. Differentiated social risk: Rebound dynamics and sustainability performance in mining. Resources Policy, v. 50, p. 19-26, 2016. Disponível em: <http://dx.doi.org/10.1016/j.resourpol.2016.08.004>. 
KOTEY, B.; ROLFE, J. Demographic and economic impact of mining on remote communities in Australia. Resources Policy, v. 42, p. 65-72, 2014.

LANE, M.; ROSS, H.; DALE, A. Social Impact Research: Integrating the Technical, Political, and Planning Paradigms. Human Organization, v. 56, n. 3, p. 302-310, 1997.

MANCINI, L.; SALA, S. Social impact assessment in the mining sector: Review and comparison of indicators frameworks. Resources Policy, v. 57, n. January, p. 98-111, 2018. Disponível em: <http://dx.doi.org/10.1016/j. resourpol. 2018.02.002〉.

MCMAHON, G.; REMY, F. (orgs). Grandes Minas y la comunidad: efectos socioeconómicos y ambientales en Latinoamérica, Canadá y España. Colombia: Centro Internacional de Investigaciones para el Desarrollo y Alfaomega Colombiana S. A., 2003.

MIRANDA, M. et al. Mining and critical ecosystems: Mapping the Risks. Washington, DC: World Resources Institute, 2003.

MITCHELL, R. K.; AGLE, B. R.; WOOD, D. J. Toward a Theory of Stakeholder Identification and Salience: Defining the Principle of Who and What Really Counts. The Academy of Management Review, v. 22, n. 4, p. 853-886, 1997. Disponível em: <http://www.jstor.org/stable/259247\%0Ahttp://about. jstor.org/terms>.

ROSYIDA, I.; KHAN, W.; SASAOKA, M. Marginalization of a coastal resource-dependent community: A study on Tin mining in Indonesia. The Extractive Industries and Society, v. 5, p. 165-176, 2018.

SOLOMON, F.; KATZ, E.; LOVEL, R. Social dimensions of mining: Research, policy and practice challenges for the minerals industry in Australia. Resources Policy, v. 33, n. 3, p. 142149, set. 2008.

VANCLAY, F. Conceptualising Social Impacts. Environmental Impact Assessment Review, v. 22, n. 3, p. 183-211, 2002. Disponível em: <http://www.sciencedirect.com/science/article/pii/S0195925501001056>.

VANCLAY, F. International Principles for social impac assessment. Impact Assessment and Project Appraisal, v. 21: 1, p. 5-12, 2003.

WEBLER, T.; KASTENHOLZ, H.; RENN, O. Public participation in impact assessment: A social learning perspective. Environmental Impact Assessment Review, v. 15, n. 5, p. 443463, 1995.

YIN, R. K. Estudo de Caso: Planejamento e Métodos. 5. ed. Porto Alegre: Bookman, 2015. 